\title{
Simulation and Analysis of Influencing Factors of Solar Energy Inter-seasonal Soil Heat Storage
}

\author{
Ping Lin ${ }^{1}$, Xiangzhi $\mathrm{Yao}^{2}$, and Yunpeng Bai ${ }^{2, *}$ \\ ${ }^{1}$ Shandong Huayu University of Technology, College of Energy and Environmental Engineering, 253034, Dezhou, Shandong, China \\ ${ }^{2}$ Dezhou Transportation Development New Energy Co., Ltd, 253000, Dezhou, Shandong, China
}

\begin{abstract}
Taking an office building in Jinan as an example, the simulation model of solar inter-seasonal soil heat storage was established by TRNSYS software, and the variation law of ground temperature in the heat storage period was analyzed. From the perspective of ground temperature change, the influence of the spacing, length, number of drilling wells and area of solar collector on the heat storage effect was analyzed. The results showed that the soil temperature increased rapidly at the beginning of heat storage, and then the temperature rise rate gradually slowed down. The ground heat exchanger spacing, length, number of drilling and collector area will have a great influence on the solar energy seasonal heat storage effect. Therefore, in practical engineering applications, for the solar inter-seasonal soil heat storage system, the parameters of buried pipes, collectors and other components are recommended to be reasonably determined by simulation to obtain the optimal heat storage effect.
\end{abstract}

\section{Introduction}

The energy of ground source heat pump system comes from underground energy. The system does not emit any waste gas, waste water and waste residue to the outside world. In recent years, ground source heat pump system can be widely used in office buildings, hotels, schools, dormitories, hospitals, hotels, shopping malls, villas, housing and other fields due to its advantages of renewable, economic benefits and long service life. The ideal operation of the ground source heat pump system is that the heat obtained from the soil in winter is balanced with the heat released into the soil in summer, so the average temperature of the soil will not change after longterm operation of the system.

However, in cold and severe cold regions of China, soil temperature may decrease year by year during longterm operation of ground source heat pump system, which is not conducive to long-term efficient and stable operation of heat pump system ${ }^{[1]}$. Solar energy interseasonal soil heat storage is the combination of solar energy and ground source heat pump, that is, the use of soil in spring, summer, autumn three seasons more abundant solar energy into heat stored in the underground soil, winter heating season will be taken out to provide heat for buildings. This not only reduces the environmental pollution caused by building heating, but also uses clean energy to alleviate energy pressure ${ }^{[2]}$. Since solar inter-seasonal soil heat storage can effectively alleviate the risk of ground temperature imbalance, it has gradually been paid attention to in recent years ${ }^{[3]}$. Bakirci

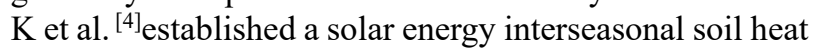

storage experimental system in Turkey. The system runs well, and the energy efficiency ratio of the ground source heat pump system is between 3.0 and 3.4. Zhu Jialing et al. ${ }^{[5]}$ established a mathematical model of solar-soil heat storage and carried out experimental analysis, analyzed the feasibility of solar energy in non-heating season soil heat storage, indicating that the heat storage effect is affected by heat storage mode, solar radiation intensity, geological conditions and many other aspects.

Solar-soil heat storage is the scientific and systematic use of solar energy and soil heat to achieve the effect of energy complementarity. In winter, the radiation amount of solar energy is relatively small, and the heat users use the heat in the soil to meet the heating load in the building. In the summer with sufficient sunlight, the sun can often provide a large amount of heat. However, the heat demand of users in this period is relatively small.

Based on this, the combination of solar soil heat storage and ground source heat pump can not only ensure the heating effect of the system, but also timely supplement the soil temperature in summer, providing feasible conditions for the long-term operation of ground source heat pump, and reducing the harm to the environment in the operation process of ground source heat pump system.

Based on the above background, this paper takes an actual ground source heat pump project in Jinan City, Shandong Province as an example, focuses on the influencing factors of solar cross-seasonal soil heat storage from the perspective of soil temperature change, and from the perspective of heat exchanger spacing, length, drilling number and solar collector area on heat

\footnotetext{
* Corresponding author: lping_0307@163.com
} 
storage effect is analyzed from the perspective of ground temperature change, aiming to provide a theoretical basis for the design and operation management of solar crossseasonal heat storage.

\section{Model establishment}

\subsection{Calculation parameters}

The research object is a practical project in Jinan City, Shandong Province ${ }^{[6]}$. The building type is an office building, in which the building area is $4513.61 \mathrm{~m}^{2}$, the building height is five layers, and the building is an energy-saving building. The ground source heat pump system is used in winter heating season, heating time is November 16 to March 15 next year. According to the hourly simulation results, the cumulative heat load in winter heating season is $186227.56 \mathrm{~kW}$. Outdoor vertical buried pipe heat transfer hole number of 56, parallel connection, depth of 100 meters, installation of DN32 specifications single U-shaped high density polyethylene pipe. The average soil thermal conductivity is $1.53 \mathrm{~W} /$ $(\mathrm{m} \cdot \mathrm{K})$, the average specific heat capacity is $2100 \mathrm{~kJ} /$ $\left(\mathrm{m}^{3} \cdot \mathrm{K}\right)$, and the average soil temperature is $15^{\circ} \mathrm{C}$. The solar collector area is $270 \mathrm{~m} 2$, and the inclination angle is $55^{\circ}$. The solar thermal storage period in spring and autumn transition season and summer is from March 16 to October $31(1824 \mathrm{~h}-7344 \mathrm{~h})$, and the start and stop time is from $9: 00$ to $17: 00$.

\subsection{TRNSYS model}

Based on the above description, a solar inter-seasonal soil heat storage simulation model was established through TRNSYS platform, Fig. 1 is a simulation diagram. Among them, Type557a is used for the ground heat exchanger module, Type14 is used for the start-stop time control of heat storage, and the meteorological data are used for the typical year of Jinan City, which are imported into the simulation model by Type15 - 3 .

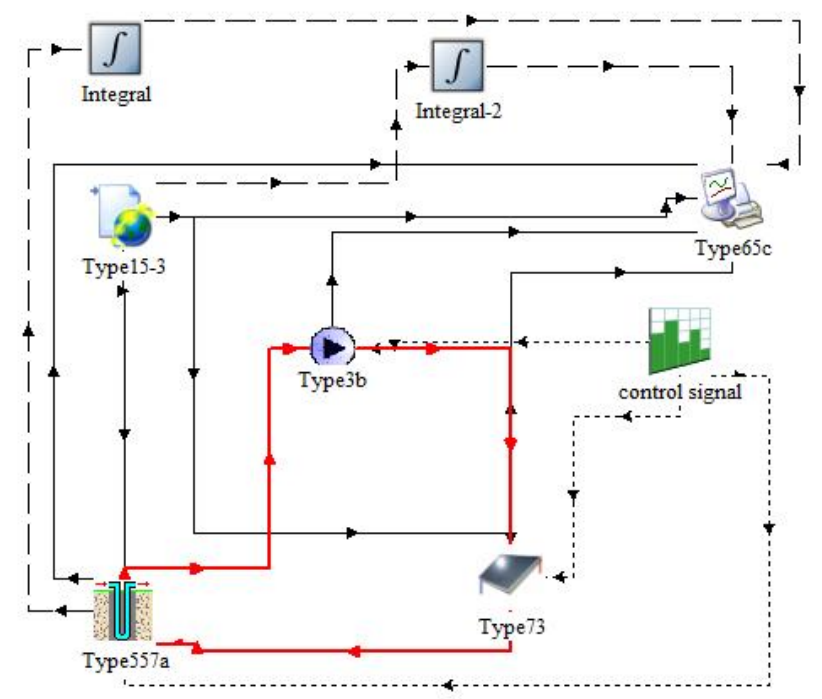

Figure 1. TRNSYS simulation diagram.
Fig. 2 and Fig. 3 show the annual temperature and solar radiation changes in typical years of Jinan City. The region is a warm temperate continental climate with an annual average temperature of $14.9^{\circ} \mathrm{C}$, and the average temperature in the hottest month ( July) is $26.9^{\circ} \mathrm{C}$. The area is rich in solar energy resources, and the annual cumulative solar radiation is $4673.3 \mathrm{MJ} / \mathrm{m}^{2}$. Among them, the solar radiation in autumn and winter is less, 969.1 MJ / $\mathrm{m}^{2}$ and 715.8 MJ / $\mathrm{m}^{2}$, respectively. Solar radiation in spring and summer is $1525.2 \mathrm{MJ} / \mathrm{m}^{2}$ and $1466.1 \mathrm{MJ} / \mathrm{m}^{2}$ respectively. In addition, solar radiation in July ( $428.3 \mathrm{MJ} / \mathrm{m}^{2}$ ) was lower than in the nearby month, mainly due to heavy rains.

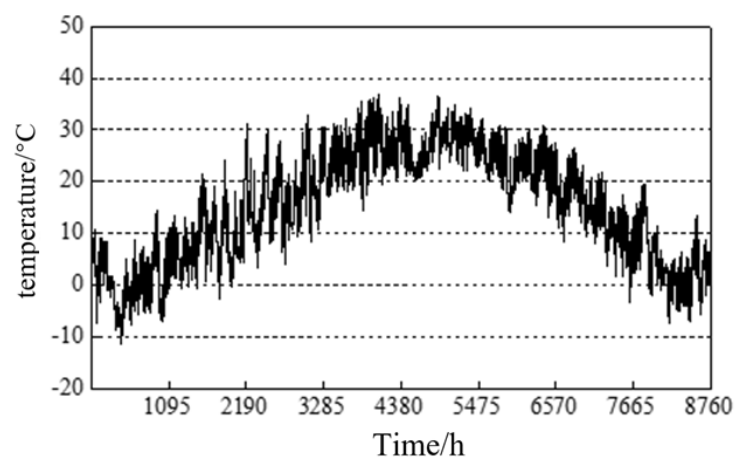

Figure 2. Temporal variation of temperature in typical years in Jinan City.

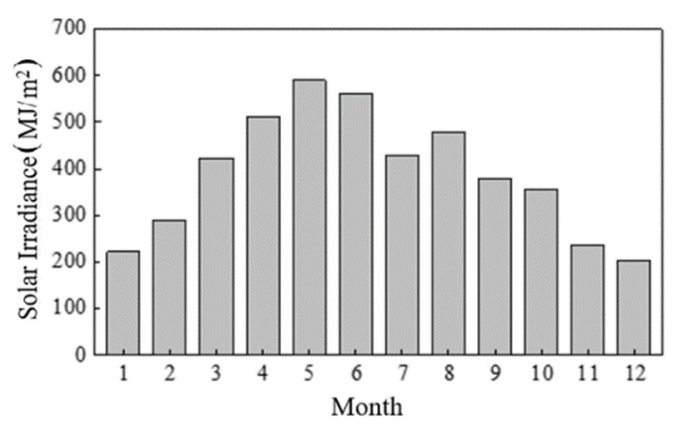

Figure 3. Changes of solar radiation in typical years in Jinan.

\section{Results and discussion}

\subsection{Effect of buried pipe on heat storage}

Fig. 4 gives the curves of average temperature of underground soil under different buried pipe spacing, in which the heat storage period is from March 16 to October 31 ( $1824 \mathrm{~h}-7344 \mathrm{~h}$ ). It can be seen that the temperature rise rate of soil is faster at the beginning of heat storage, and then the temperature rise rate is gradually gentle. For example, when the local buried pipe spacing was $4.5 \mathrm{~m}$, by August $31(5880 \mathrm{~h}$ ), the average temperature rise rate of underground soil was $0.097{ }^{\circ} \mathrm{C} / \mathrm{d}$, compared with $0.0048{ }^{\circ} \mathrm{C} / \mathrm{d}$ from September 1 ( $5881 \mathrm{~h}$ ) to October 31 $(7344 \mathrm{~h})$. This is because the soil temperature is at a low level in the early stage of heat storage, and the temperature difference between the outlet water temperature of solar collector and the soil is large, which is conducive to the heat transfer on the soil side. On the 
other hand, the solar radiation intensity in autumn is weaker than that in spring and summer, and the solar collector obtains less heat. In addition, with the increase of ground heat exchanger spacing, the average soil temperature decreased. At the end of the heat storage period, the ground temperature of four different buried pipe spacing is $17.9^{\circ} \mathrm{C}, 16.9^{\circ} \mathrm{C}, 16.4^{\circ} \mathrm{C}, 16.1^{\circ} \mathrm{C}$. Thus, different buried pipe spacing has a more obvious effect on the average soil temperature. However, it is worth noting that too small buried pipe spacing will aggravate the soil thermal accumulation effect and increase the difficulty of transferring heat to the outside soil to a certain extent.

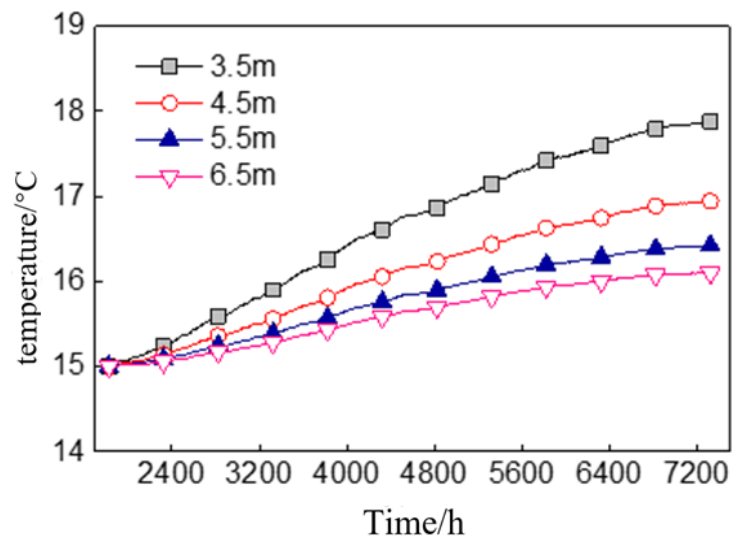

Figure 4. Ground temperature variation curve under different buried pipe spacing.

Fig. 5 further shows the variation curves of soil average temperature under different buried pipe depths. It can be seen that when other parameters remain unchanged, the buried pipe depth will also have a greater impact on the average soil temperature. For example, when the buried depth was $60 \mathrm{~m}$ and $140 \mathrm{~m}$, the average soil temperature increased by $2.1{ }^{\circ} \mathrm{C}$ and $1.4{ }^{\circ} \mathrm{C}$, respectively, which were about $14.0 \%$ and $9.3 \%$ higher than those in the initial stage. According to the author's previous research results, the change of buried pipe depth and spacing has a great influence on the construction cost and proportion area of the project. Therefore, the buried pipe form should be selected according to local conditions after hourly numerical simulation throughout the year.

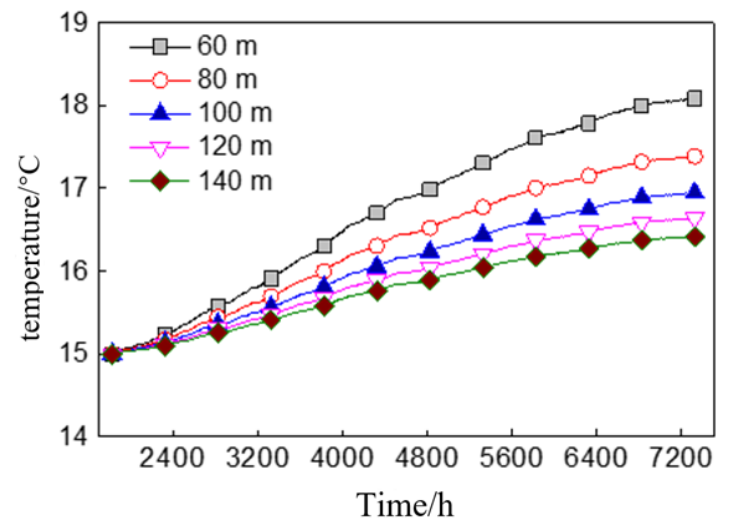

Figure 5. Ground temperature curves under different buried pipe depths.

In order to further analyze the influence of the number of buried pipe drilling on solar inter-seasonal soil heat storage, Fig. 6 shows the variation curves of ground temperature with different drilling numbers. It can be seen that different drilling depths also affect the change of soil average temperature. Specifically, under the premise of other factors unchanged, the more number of buried pipe drilling, the increase of soil average temperature decreases. For example, when the number of drilling wells is 36 , the rise of ground temperature is $2.7^{\circ} \mathrm{C}$. In contrast, when the number of drilling wells is 76 , the rise of ground temperature is only $1.5^{\circ} \mathrm{C}$. When the number of drilling wells was 46,56 and 66 , the average soil temperatures at the end of heat storage were $17.3{ }^{\circ} \mathrm{C}$, $16.9{ }^{\circ} \mathrm{C}$ and $16.7{ }^{\circ} \mathrm{C}$, respectively, which were about $15.3 \%, 12.6 \%$ and $10.7 \%$ higher than the initial temperature. It can be seen that the buried pipe depth, spacing, drilling number and other factors have a relatively important impact on the solar energy interseasonal heat storage effect. For such systems, the buried pipe type and layout should be reasonably determined to obtain the maximum heat storage effect, and ultimately further improve the operation efficiency of the heat pump system in winter heating season.

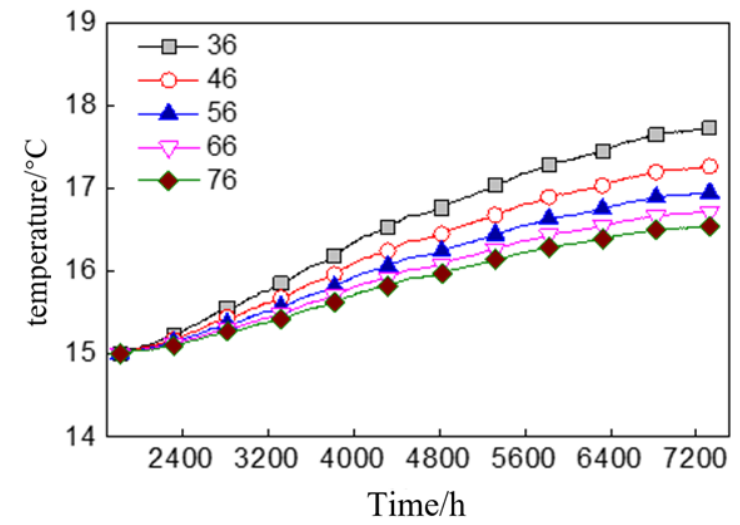

Figure 6. Ground temperature curves of different drilling numbers.

\subsection{Effects of heat collection area on heat storage}

The solar collector area directly affects the solar heat collection, thus further affecting the solar inter-seasonal soil heat storage effect. Therefore, it is crucial to select the appropriate collector area for solar inter-seasonal heat storage. Fig. 7 shows the variation curves of soil average temperature under different collector areas. It can be seen that in terms of the simulation in this paper, when other conditions remain unchanged, the average soil temperature increases with the increase of the solar collector area. For example, when the collector area was $170 \mathrm{~m}^{2}$ and $320 \mathrm{~m}^{2}$, the average soil temperature after the end of the heat storage period was $16.3^{\circ} \mathrm{C}$ and $17.2^{\circ} \mathrm{C}$, respectively, which increased by about $8.7 \%$ and $14.7 \%$ compared with the initial stage. However, it is worth noting that the collector area is increased by $88.2 \%$, and the temperature rise is only increased by $0.9^{\circ} \mathrm{C}$. It can be seen that the collector area design should be comprehensively determined by the construction cost and the cumulative heat load in winter heating season. In terms of the simulation in this paper, the collector area should be $200 \sim 270 \mathrm{~m}^{2}$. 


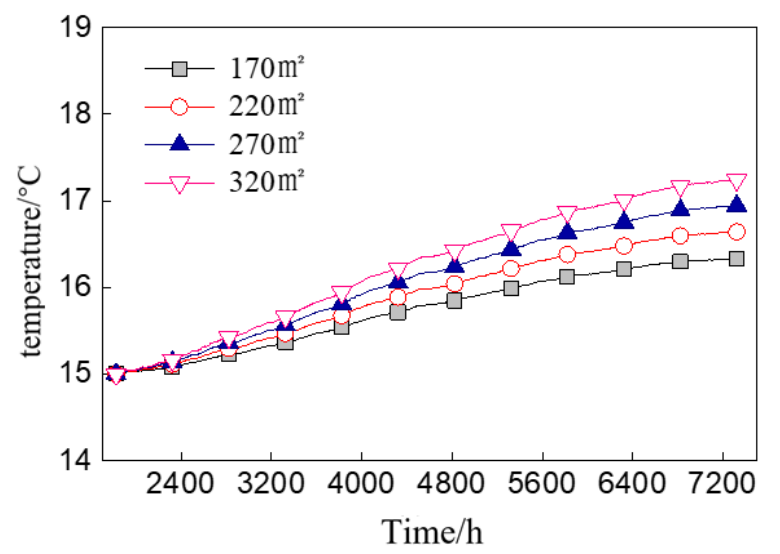

Figure 7. Ground temperature curve under different collector area.

\section{Conclusions}

In this paper, an office building in Jinan is taken as an example to establish a solar inter-seasonal soil heat storage simulation model by TRNSYS software. The influencing factors of solar inter-seasonal soil heat storage are simulated and studied from the perspective of ground temperature change, and the variation law of ground temperature in the heat storage period is analyzed. The influence of the spacing, length, number of drilling wells and area of solar collector on the heat storage effect is analyzed from the perspective of ground temperature change. The main conclusions are as follows :

1) Without changing the parameters, the soil temperature increased rapidly at the beginning of heat storage, and then the temperature rise rate gradually slowed down. Specifically, from 16 March to 31 August, the average temperature rise rate of underground soil was $0.097{ }^{\circ} \mathrm{C} / \mathrm{d}$, compared with $0.0048{ }^{\circ} \mathrm{C} / \mathrm{d}$ from 1 September to 31 October.

Analysis reasons : on the one hand, it may be because the soil temperature is at a low level in the early stage of heat storage, and the temperature difference between the outlet water temperature of solar collector and the soil is large, which is conducive to the heat transfer on the soil side. On the other hand, it is also possible that the intensity of solar radiation in autumn is weaker than that in spring and summer, and the heat obtained by solar collectors is less, which leads to the low heating rate of soil side in autumn.

2) Ground heat exchanger spacing, length, number of drilling and collector area will have a great influence on the solar energy seasonal heat storage effect.

Specifically, when other parameters remain unchanged, the average soil temperature decreases with the increase of ground heat exchanger spacing. With the increase of buried pipe heat exchanger depth, the range of low temperature change decreases. With the increase of the number of buried pipe drilling, the increase of soil average temperature decreases. With the increase of solar collector area, the average soil temperature increased.

Therefore, in practical engineering applications, for solar inter-seasonal soil heat storage system, the parameters of buried pipes, collectors and other components are recommended to be reasonably determined by simulation to obtain the optimal heat storage effect.

\section{Acknowledgement}

This work was supported by Shandong Huayu University of Technology and Dezhou's Key Laboratory of Highefficiency Heat Pump Air Conditioning Equipmentand System Energy Saving Technology(No.26).

\section{References}

1. Rui Hua, Yiqun Pan,Rui Fan, et al. Impacting Factor on Ground Heat Balance of GSHP System Using TRNSYS [J]. Building Energy Efficiency. 2012, 40(3): 23-27.

2. Qi Hao. Optimization of Solar Energy Inter-seasonal Energy Storage Heating Application System. [D]. Hebei University of Science and Technology,2020.

3. Wenyong Zhang,Maoyu Zheng,Xiao Wang, et al. Analysis of Influencing Factors of Solar Seasonal Soil Heat Storage[J]. Building Science,2010,26(06): 81-86.

4. Bakirci K, Ozyurt O, Comakli K, et al. Energy analysis of a solar-ground source heat pump system with vertical closed-loop for heating applications[J]. Energy, 2011, 36(5):3224-3232.

5. Jialing Zhang,Jing Zhao,Wei Zhang. Solar-soil Coupled Heat Storage Characteristics and Potential Analysis. [J]. Acta Energiae Solaris Sinica,2011,32 (03):390-394.

6. Hongxin Zhu. Research on the Application of Solar Energy and Ground Source Heat Pump Combined Energy System in Building Energy Saving [D]. Shandong Jianzhu University,2016. 